\title{
Sand Textural Control on Shear-Enhanced Compaction Band Development in Poorly-Lithified Sandstone
}

\author{
Elin Skurtveit ${ }^{1,2,3}$, Gregory Ballas ${ }^{4}$, Haakon Fossen ${ }^{2,5}$, Anita Torabi $^{1}$, Roger Soliva ${ }^{4}$ and Michel Peyret ${ }^{4}$ \\ 1. University Research CIPR (Centre for Integrated petroleum Research), Allégaten 41, Bergen N-5007, Norway \\ 2. Earth Science Department, University of Bergen, Allégaten 41, Bergen N-5007, Norway \\ 3. NGI (Norwegian Geotechnical Institute), Sognsveien 72, Oslo N-0855, Norway \\ 4. Unité Mixte de Recherche Centre National de la Recherche Scientifique 5243 Geosciences Montpellier, University of Montpellier \\ II, Unité de Formation et de Recherche Sciences and Techniques, Place Eugène Bataillon, Montpellier cedex 5 34095, France \\ 5. Museum of Natural History, University of Bergen, Allégaten 41, Postboks 7800, Bergen N-5020, Norway
}

\begin{abstract}
Sand textural control on SECB (shear-enhanced compaction band) formation is analyzed combining field observations, detailed material characterization and mechanical testing for poorly lithified sandstone units in Provence (France). Field observations show that SECBs are densely distributed in a coarse-grained unit with moderate porosity (27\%), whereas few SECBs are developed within the overlying fine-grained, high-porosity (39\%) unit. Results from textural characterization show that the main difference between the two sand units is grain size and sorting, whereas they are similar with respect to composition and grain angularity. Packing density is introduced as an important parameter for comparing the compaction properties independent of the textural variations between the two units. Compaction experiments show a slightly faster compaction of the coarse-grained sand as compared to the fine-grained sand, and more pronounced grain crushing is observed in the coarse-grained unit. The results indicate that the preferential localization of SECBs to the coarse-grained unit is controlled by a slightly denser packing of the coarse-grained material at the time of band formation together with higher stress concentrations on grain contacts. Hence, this study emphasizes that porosity alone is an insufficient parameter for predicting deformation band evolution in sand (stone).
\end{abstract}

Key words: Deformation bands, localization, grain size, porosity, packing density.

\section{Introduction}

Deformation bands are tabular zones of strain localization formed in porous and granular materials such as sand and sandstone [1], carbonate grainstone [2], chalk [3] or ignimbrite [4]. Networks of deformation bands are observed in many sandstone reservoirs and are often associated with faults, but also observed around salt diapirs and within gravitational slumps [5]. The microstructure of deformation bands varies from the host rock. Porosity and permeability reduction is observed for many types of deformation bands and the bands may provide barriers or baffels to fluid flow within the reservoirs.

Corresponding author: Elin Skurtveit, Ph.D. candidate, research fields: structural geology, faults and reservoir characterization and $\mathrm{CO}_{2}$ storage. E-mail: elin.skurtveit@ngi.no.
Several recent publications provide quantitative data on the petrophysical properties of deformation bands [6-11] and more detailed separating deformation bands into compaction bands and shear enhanced compaction bands [12, 13].These properties provide valuable input for reservoir models [14-16] and the understanding of reservoir flow properties. Recently, structural heterogeneities have received new interest in reservoir simulations for $\mathrm{CO}_{2}$ storage [17] and for geomechanical modeling describing effects of pore pressure during $\mathrm{CO}_{2}$ injection [18]. In order to define critical pressure to avoid reservoir failure during $\mathrm{CO}_{2}$ injection [19], a better understanding of controlling parameters for strain localization and the formation of deformation bands in porous sandstones are needed.

Deformation bands are usually classified by their 
kinematics: dilation, shear or compaction; and by the deformation mechanisms responsible for their microstructures: disaggregation (grain rolling or slipping), cataclasis (grain crushing or splitting) or diagenetic processes (pressure-solution or cementation) [5]. The characteristics of these bands are controlled by numerous factors, such as tectonic setting, burial depth and the constitutive parameters of the host rock [20-22]. Recent studies on deformation band patterns in porous sandstone indicate that deformation bands in contractional regime are generally well distributed, whereas bands tend to be localized in fault damage zones in extensional regime [23-25]. An intensification of cataclastic processes is generally observed with increasing burial depth [5, 12, 26-29]: from dissaggregation [28, 30] and low-intensitycataclasis $[12,13]$ in shallow burial conditions to intense cataclasis in deeply buried sandstones [5, 31]. However, examples of intense cataclasis are also described in deformation bands formed within shallowly buried sandstones [24, 32] suggesting that factors other than burial depth influence the deformation mechanism involved during deformatin of porous sand (stone). More specifically, the mechanical compaction and evolution of the sand textural characteristics during burial [33, 34] appear to be important and need to be better explored.

The influence of constitutive parameters of host sandstone on the deformation is intensively analyzed both through field descriptions and laboratory experiments. Field examples described in eolian sandstones display compaction bands that selectively form in specific high-porosity and coarse-grained layers [35, 36]. Sandstones and sands of different composition, sorting, and porosity have been tested through laboratory experiments over the last decades and reviewed by Wong and Baud [37]. These tests confirm the importance of textural parameters, such as porosity and grain size, on the strength of sandstone [38, 39] and sand [40]. However, the influence of initial packing [41], grain sorting [42, 43] and grain angularity
[44] on the mechanical properties of sandstone and band localization remains poorly understood and need to be further addressed.

In the Uchaux sands in Provence, France, shear-enhanced compaction bands [12] are observed to be specifically located to coarse-grained and less porous sand units [13], in contradiction to the deformation bands at the Buckskin Gulch, Utah, where bands selectively form in layers with both large grain size and high porosity. Mechanical tests on the Uchaux sands showed that the most coarse-grained and low-porosity sand developed the most pronounced strain localization structures [45]. In the current work, we present detailed textural characterization and mechanical testing in an attempt to better understand the selective formation of deformation bands in specific sand units. The sand packing density is introduced as an important and useful parameter for comparing deformation and yield strength for shallowly buried sands with different porosity and textural characteristics. The results are discussed and compared with the established theoretical model that relates grain packing, fracturing and yield stress.

\section{Field Location and Deformation Bands}

The study area is located in the Boncavaï quarry in the western part of the "Bassin du Sud-Est" in Provence, France (Fig. 1). Several Upper Cretaceous sand-dominated deposits crop out in this area, showing networks of deformation bands [24, 25]. In the present study, we focus on the SECB (shear-enhanced compaction bands) formed under the Eocene shortening and generally observed in the Turonian Uchaux Sands (Fig. 1) [13]. The Uchaux Sands constitute a $~ 120$ m thick formation composed of meter to multi-meter thick units of poorly lithified sandstones. Due to the shallow burial depth (maximum burial depth of $400 \pm 100 \mathrm{~m}$ ), these poorly lithified sandstones easily disintegrate into sand and are referred to as sand in the characterization part of this paper. The sand represent deltaic tidal bar to beach deposits, and show large variations in porosity and 


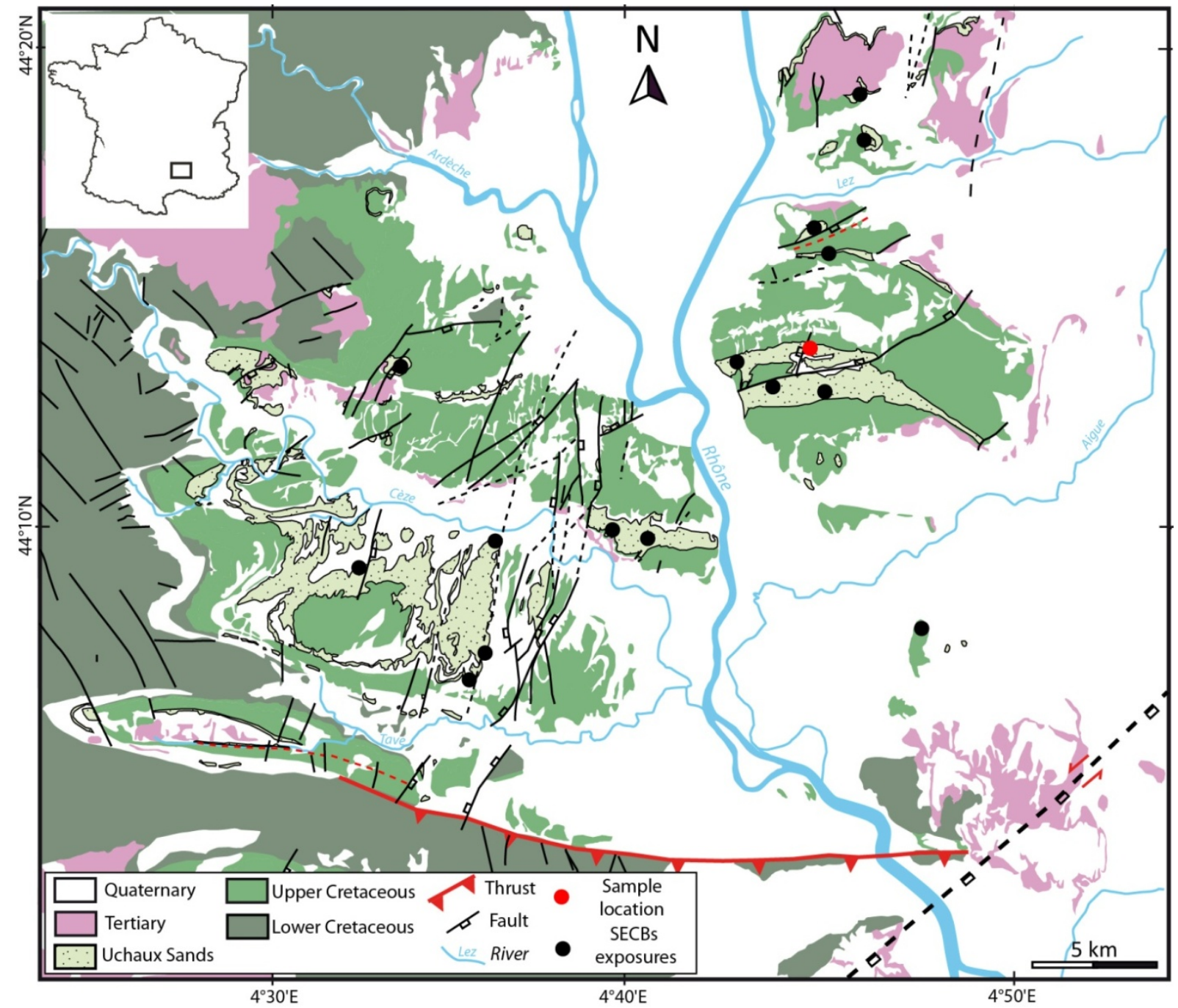

Fig. 1 Geological map of the "Bassin du Sud-Est", Provence, France (after Ref. [13]). The Boncavaï quarry study area is plotted as a red dot.

grain-size distribution, varying from fine to coarse sand.

The SECBs in Uchaux are millimeter to centimeter thick strands that are generally revealed by their positive relief resulting from their higher resistance to erosion as compared to the host sandstone (Fig. 2a). These bands show no visual apparent offset of the oblique laminas (Fig. 2b), and can be shown to involve similar (mm-scale) amounts of compaction and reverse-shear offset [20]. They are organized into conjugate sets showing a range in dihedral angle from $81^{\circ}$ to $90^{\circ}$. The SECBs show limited degree of cataclasis (Fig. 2c), revealed by a small grain size reduction, corresponding to crush microbreccia in the classification [46].

Distributed networks of SECBs are only developed in certain sandstone units (Fig. 2) [13]. This restricted occurrence is well exposed in the Boncavaï quarry, where two different units within the Uchaux Sands occur: (1) a fine-grained unit showing only a few scattered SECBs, and (2) an underlying coarse-grained unit, showing well-distributed network of SECBs (Fig. 2a). Most of the SECBs located in the coarse-grained unit stop at the boundary with the fine-grained unit. Only a few bands are observed to continue from the coarse-grained layer into the fine-grained unit (Fig. 2b). Slightly higher grain size reduction is observed within the SECBs formed in the coarse-grained unit compared 
to the SECBs formed in the fine-grained one. Grains are also slightly more cracked in bands from the coarse-grained unit (88\% fractured grains) than in the fine grained unit (79\% fractured grains). Comparable compaction of less than $6 \%$ porosity reduction is measured for bands in both units.

\section{Material Characterization and Methods}

The two Uchaux Sand units studied are referred to as the coarse-grained and the fine-grained units, respectively (Fig. 3). Even though they display similar compositions (quartz: 95\%-96.5\%, feldspar: 3-4.5\%, clay and iron oxide: $0.5 \%$ ), the two sands differ in porosity, grain size and grain sorting (Table 1). The porosity is measured by mercury injection porosimetry on intact samples of the host rock and the bands. The grain size distribution and sorting are characterized using standard sieving analyses from disintegrated sand samples (Fig. 4). Grain size is described by the mean grain size represented by the diameter at $50 \%$ passing, $d_{50}$, whereas sorting is given as the uniformity coefficient $\left(\mathrm{Cu}=d_{60} / d_{10}\right)$; a sand is considered as uniform for a $\mathrm{Cu}$ less than 4 [47]. The coarse-grained sand (Fig. 3a) has an average porosity of $27.3 \%$, a mean grain size of $0.65 \mathrm{~mm}$, and a uniformity coefficient of 4.1 , whereas the finer-grained sand (Fig. 3b) has an average porosity of $38.8 \%$, a mean grain size of $0.23 \mathrm{~mm}$, and a uniformity coefficient of 1.7 , which means that the fine-grained sand is better sorted than the coarse-grained one (Table 1).

The coordination number, $C$, corresponding to the average number of contact points between a single grain and its surrounding grains [48], is estimated for each grain in two perpendicular 2D SEM (scanning electron microscope) photomicrographs for each unit. This estimated coordination number equals 7.1 in the coarse-grained unit and 5.6 in the fine-grained unit. These values are in the lower range compared to random packs of identical spheres, which range from 6.9 (loose packing) to 9.1 (dense packing) [49]. Partly,
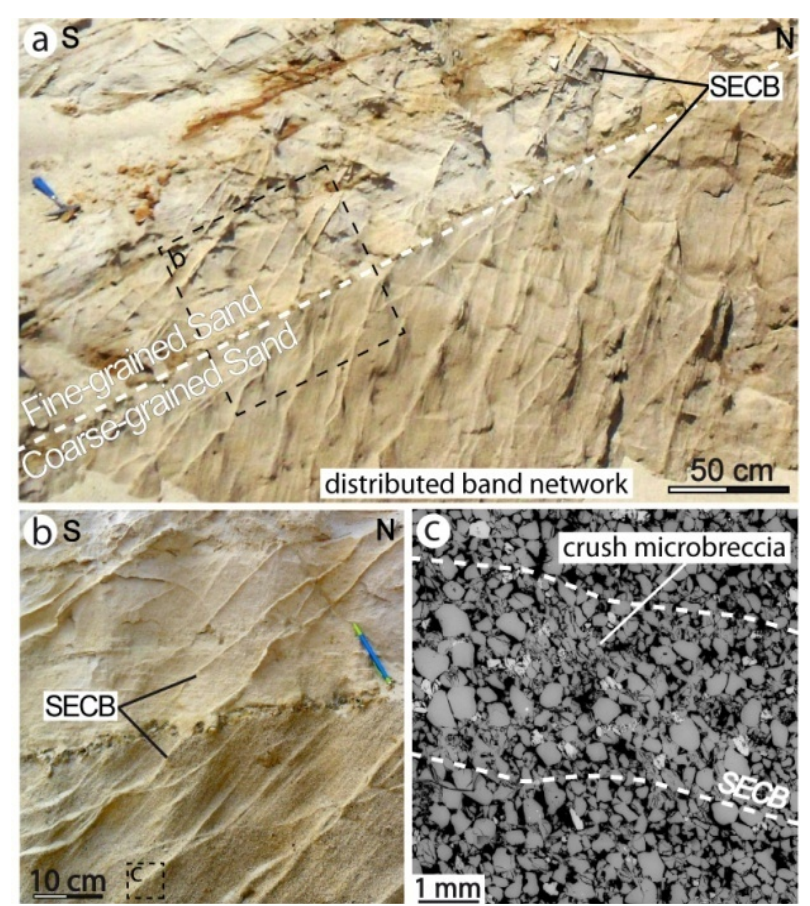

Fig. 2 (a) Outcrop showing different SECBs patterns in the different Uchaux sand units at the Boncavaï quarry; (b) detailed view of the contact between the two different units; (c) SEM photomicrograph showing the microstructure of a SECB located in the coarse-grained unit.

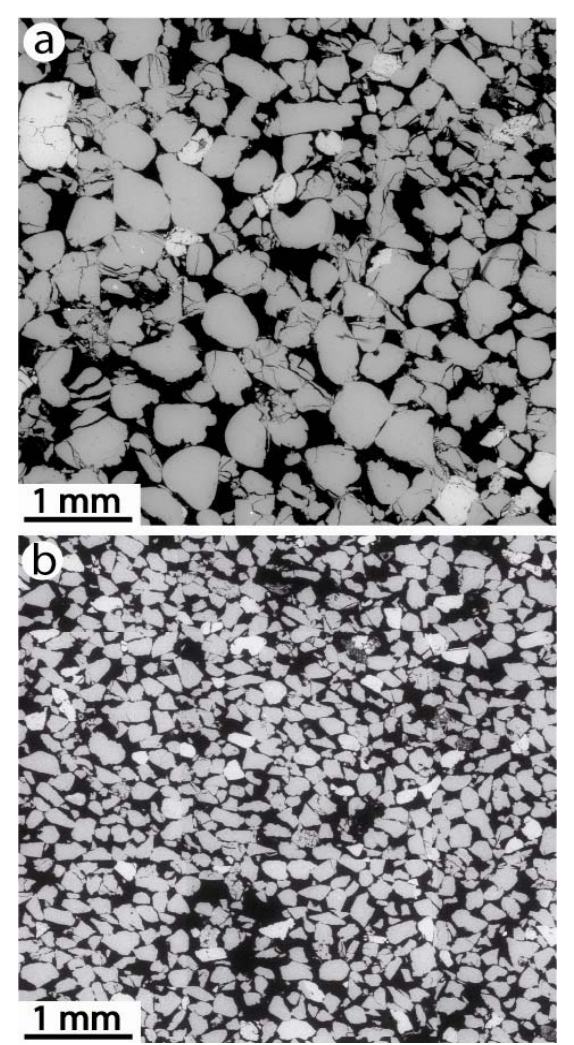

Fig. 3 SEM photomicrographs showing the texture of the (a) coarse-grained and (b) fine-grained Uchaux Sand units. 
Table 1 Material characteristics of the fine- and coarse-grained units of the Uchaux Sand, Boncavaï quarry. Grain size, sorting and relative packing density were measured on disintegrated sand samples, the porosity for the disintegrated sand was calculated from the corresponding relative density. Porosity for the host rock and SECB was measured using porosimetry, and the corresponding relative density was inferred from the relative density and porosity relationship found for the disintegrated sample. Coordination number is calculated from SEM photomicrographs.

\begin{tabular}{|c|c|c|c|c|c|c|c|c|}
\hline Unit & Material & $\begin{array}{l}\text { Mean } \\
\text { grain size } \\
d_{50} \\
(\mathrm{~mm})\end{array}$ & $\begin{array}{l}\text { Peak grain size } \\
d_{\max } \\
(\mathrm{mm})\end{array}$ & $\begin{array}{l}\text { Sorting } \\
d_{60} / d_{10}\end{array}$ & Angularity & \begin{tabular}{|l|} 
Coordination \\
number \\
$C$ \\
(contacts/grain)
\end{tabular} & $\begin{array}{l}\text { Relative } \\
\text { density } \\
D r \\
(\%)\end{array}$ & $\begin{array}{l}\text { Porosity } \\
n \\
(\%)\end{array}$ \\
\hline \multirow{5}{*}{ Coarse-grained } & \multirow{3}{*}{ Disintegrated sand } & 0.65 & 1.1 & 4.1 & $\begin{array}{l}\text { Subrounded } \\
\text { to rounded }\end{array}$ & & $D r_{\min (0)}$ & 45 \\
\hline & & & & & & & $D r_{50}$ & 37 \\
\hline & & & & & & & $D r_{\max (100)}$ & 27 \\
\hline & Host rock & & & & & 7.1 & 98 & 27.3 \\
\hline & SECB & & & & & & 109 & 24.4 \\
\hline \multirow{5}{*}{ Fine-grained } & \multirow{3}{*}{ Disintegrated sand } & 0.23 & 0.27 & 1.7 & \begin{tabular}{|l|} 
Subrounded \\
to rounded
\end{tabular} & & $D r_{\min (0)}$ & 54 \\
\hline & & & & & & & $D r_{50}$ & 47 \\
\hline & & & & & & & $D r_{\max (100)}$ & 37 \\
\hline & Host rock & & & & & 5.6 & 94 & 38.8 \\
\hline & SECB & & & & & & 116 & 33.6 \\
\hline
\end{tabular}

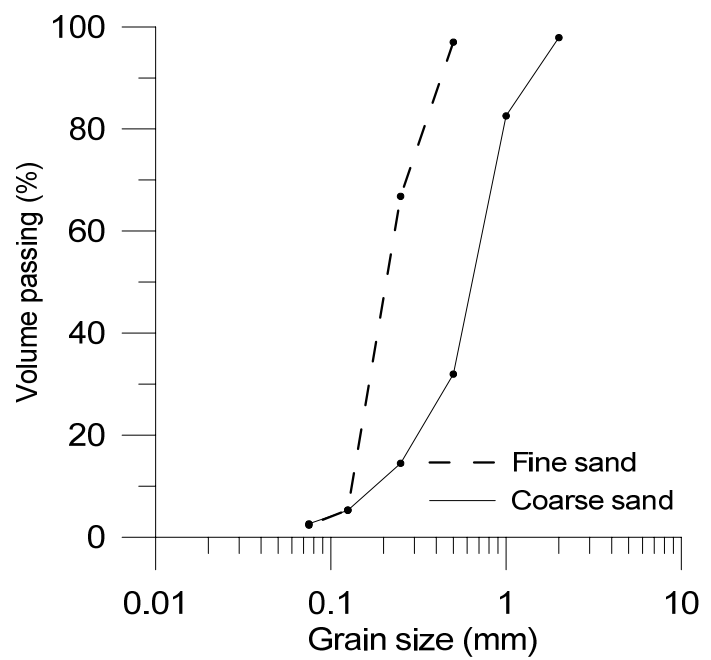

Fig. 4 Grain size distributions for the fine- and coarse-grained sand studied.

this can be attributed to the $2 \mathrm{D}$ counting of grain contacts from images, but grain contacts in natural sands-grains are also expected to be lower than for random packs of identical spheres as they are not purely spherical. The higher coordination number for the low porosity, coarse-grained material than for the more porous fine-grained material is in agreement with models for coordination number where the coordination number increases with decreasing porosity [49].
The grain angularity is estimated using shape parameters described in Ref. [47]. These parameters are calculated from photomicrographs of representative numbers of disaggregated grains from both sand units (Appendix A). Two sands are classified as subrounded to rounded (Fig. A1). The fine-grained sand is slightly more angular than the coarse-grained sand. We note that inherited grain fracturing is observed in both materials (Fig. 3).

The relative density describes the compaction of sand based on the packing of sand grains relative to the highest and lowest packing (or porosity) obtained using a given method in the laboratory. The minimum dry density, $D r_{\text {min }}$, determines the loosest packing (highest porosity) of sand achievable in the laboratory. $D r_{\min }$ is determined by filling a mould slowly with dry sand and then measuring the weight of sand. Maximum dry density, $D r_{\max }$, is defined as the densest packing (lowest porosity) of the material. $D r_{\max }$ is determined by packing sand using vibration at a pressure of 70-100 Newton for ca. $30 \mathrm{~s}$. Based on the maximum and minimum dry density, the relative density can be calculated for the sand and related to the minimum and maximum values of void ratio and porosity [50]. The 
relative density, $D r$, is defined as

$$
D r=\frac{\gamma_{d, \max }}{\gamma_{d}} \times \frac{\gamma_{d}-\gamma_{d, \min }}{\gamma_{d, \max }-\gamma_{d, \min }} \times 100=\frac{e-e_{\max }}{e_{\min }-e_{\max }}
$$

where, $\gamma_{d}$ is the dry density of the sand and $e$ is the void ratio. The void ratio is defined as

$$
e=\frac{n}{1-n}
$$

where, $n$ is the porosity. Based on the measured host rock porosity for each unit, the relative density of $94 \%$ for the fine-grained unit and $98 \%$ for the coarse-grained unit are estimated (Table 1). This shows that the field porosity measured corresponds to the maximum packing density achievable in the laboratory using mechanical compaction with minor grain damage for both materials. This observation is supported by the field observation that there is very limited evidence of chemical compaction in the two formations. Inside the SECB, the average porosity corresponds to average relative density of $109 \%$ and $116 \%$ for the coarse-grained unit and fine-grained unit, respectively. This is higher than the maximum packing density, $D r_{\max }$, measured in the laboratory, reflecting the effect of localization and grain crushing in the naturally formed SECBs.

\section{Results from Compaction Experiments}

Deformation characteristics for the two sands studied are investigated using triaxial loading tests at 5 MPa effective confining pressure. Fine-grained sands and coarse-grained sands are compared using a loose initial packing density ( $D r 55 \%$ ). The effect of the initial packing density is investigated by comparing a loose ( Dr 55\%) and a dense ( $\sim \operatorname{Dr}$ 85\%) initial packing for the fine-grained sand. An overview of the tests and test conditions is given in Appendix B.

Vertical strain, porosity, relative packing density and relative porosity reduction versus effective mean stress are compared in Fig. 5 for both the isotropic loading stage (up to $5 \mathrm{MPa}$ ) and during axial loading. All three materials show a small vertical strain under the isotropic loading, slightly higher for the loosely packed sand than for the densely packed sand (Fig. 5a).
Loosely packed sand of coarse and fine grain size show a similar axial strain evolution, whereas the densely packed sand shows a better defined yield point during axial loading (Fig. 5a). Loosely packed sands show considerable compaction both during isotropic and axial loading (Fig. 5b). The coarse-grained sand shows a slightly faster compaction than the fine-grained sand for the first part of the test (Fig. 5b). Densely packed sand shows less compaction than the loose sand (Fig. 5b). All the tests are approaching a similar relative density close to $\operatorname{Dr} 100 \%$ during axial loading. The initial porosity for the three sands differs largely, with the highest porosity found for the loosely packed, fine-grained sand and the lowest porosity for the loosely packed, coarse-grained sand (Fig. 5c). The densely packed, fine-grained sand shows less porosity reduction than the loosely packed materials, whereas the coarse-grained sand shows the largest porosity reduction (Fig. 5d). Based on the comparison of the two materials and initial packing density, it is observed that the coarse-grained sand has a higher compressibility than the fine-grained sand (Fig. 5). The fine-grained sand is found to be slightly stiffer than the coarse-grained sand during compaction and shows a slightly better defined yield. The best defined yield is observed for the densely packed fine sand, possibly reflecting more localized deformation compared to that of the loosely packed sands.

Photomicrographs from post-test thin sections show various types of grain breakage, such as gf (grain flaking) where deformation is localized to grain edges, $\mathrm{S}$ (single) fractures where individual grains split in two, IC (irregular complex) fractures where grains are split in several parts in a complex pattern, and grain cr (crushing) where grains are completely crushed into smaller aggregates [51]. Grain crushing is most pronounced for the coarse-grained sand, whereas the dense sand show slightly more grain fracturing than the loose sand (Fig. 6). The observed fracturing confirms that onset of grain fracturing and crushing occurs during axial compaction below a mean stress of 10-12 

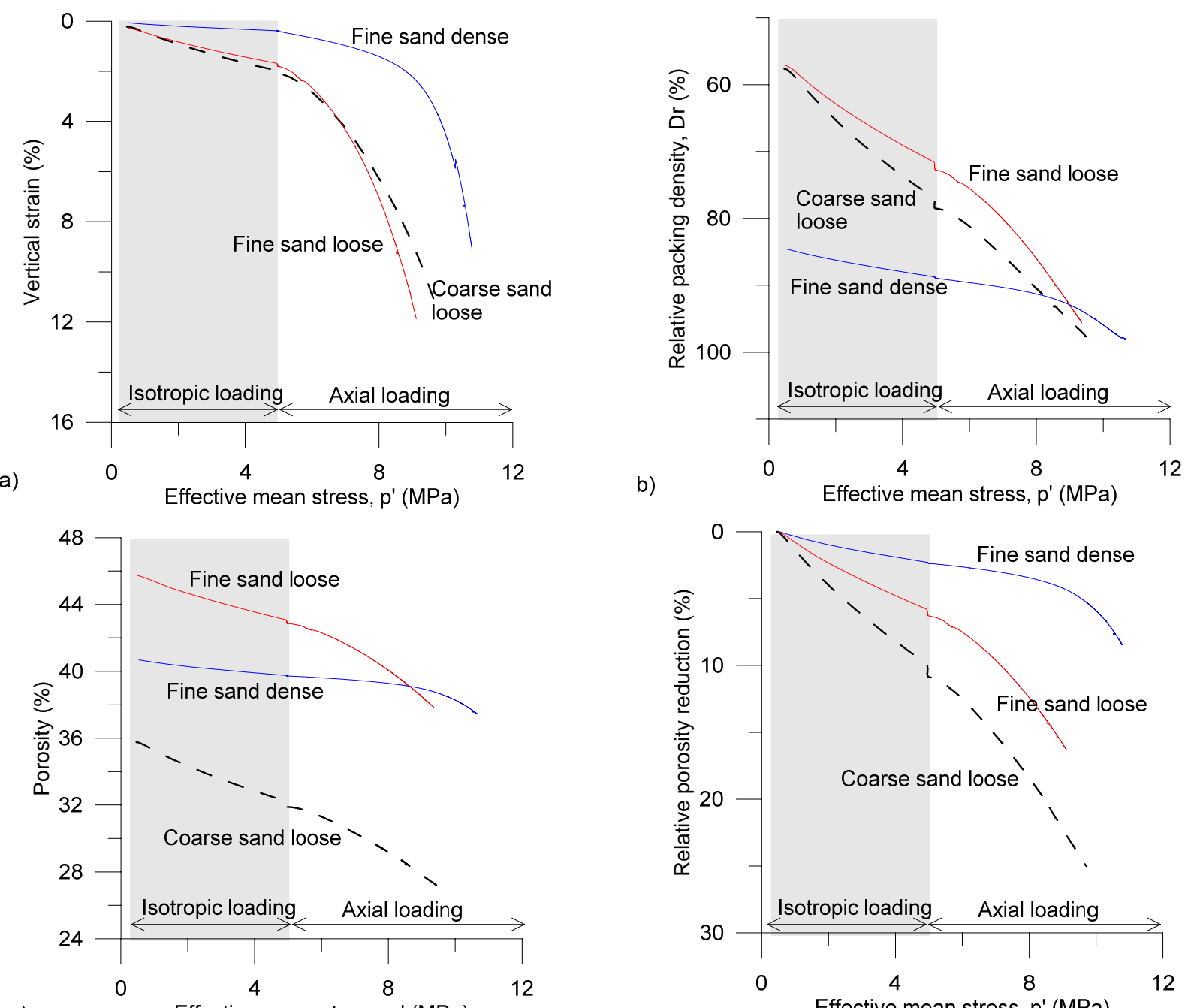

c) Effective mean stress, $p^{\prime}(\mathrm{MPa})$

d)

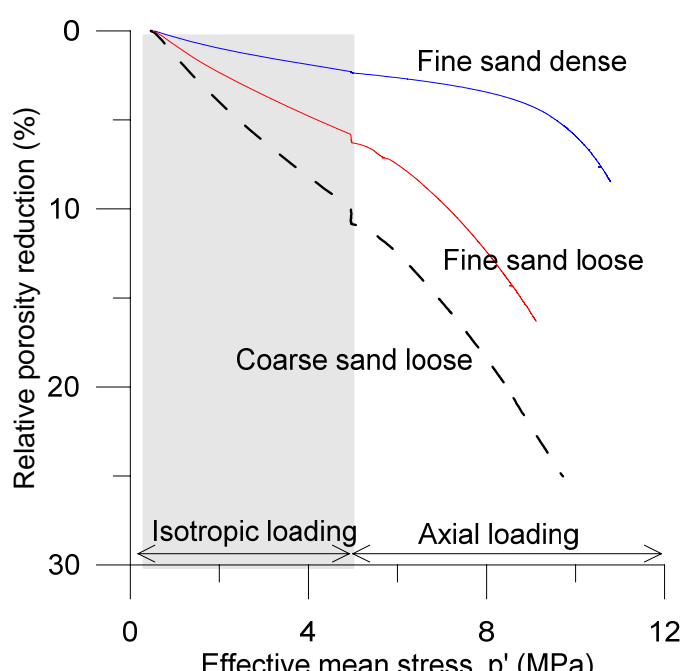

Fig. 5 Graphs showing the evolution of (a) the vertical strain, (b) the relative packing density (Dr), (c) the porosity, and (d) the relative porosity reduction as a function of effective mean stress $P^{\prime}$ for the tested sands. The grey part of graphs corresponds to the isotropic loading up to $5 \mathrm{MPa}$ whereas the white part corresponds to the axial loading.
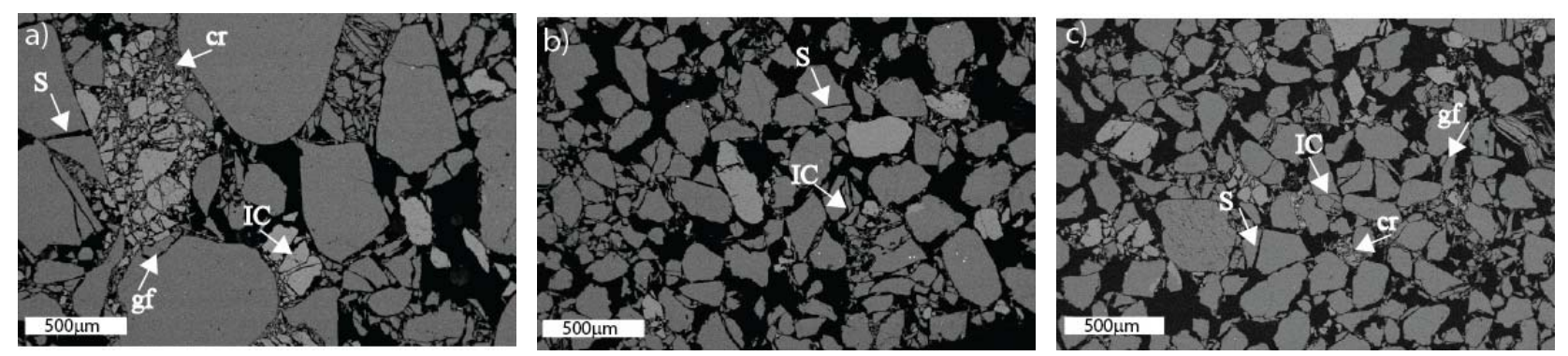

Fig. 6 SEM photomicrographs showing different types of grain damage: gf (grain flaking), S (single) fractures, IC (irregular complex) fractures and zones with cr (crushed) grains for (a) the coarse-grained, (b) loose fine-grained and (c) dense fine-grained sands. More grain crushing is observed in the coarse-grained material than in the fine-grained, although some large grains are not damaged. The dense packing (c) shows slightly more grain damage than the loose packing (b).

MPa for both the fine-grained and coarse-grained sands.

Triaxial loading tests at $5 \mathrm{MPa}$ are compared with a hydrostatic loading test (isotropic conditions) from the fine-grained sand with loose initial packing (Fig. 7). The packing density is found to be very sensitive to the 


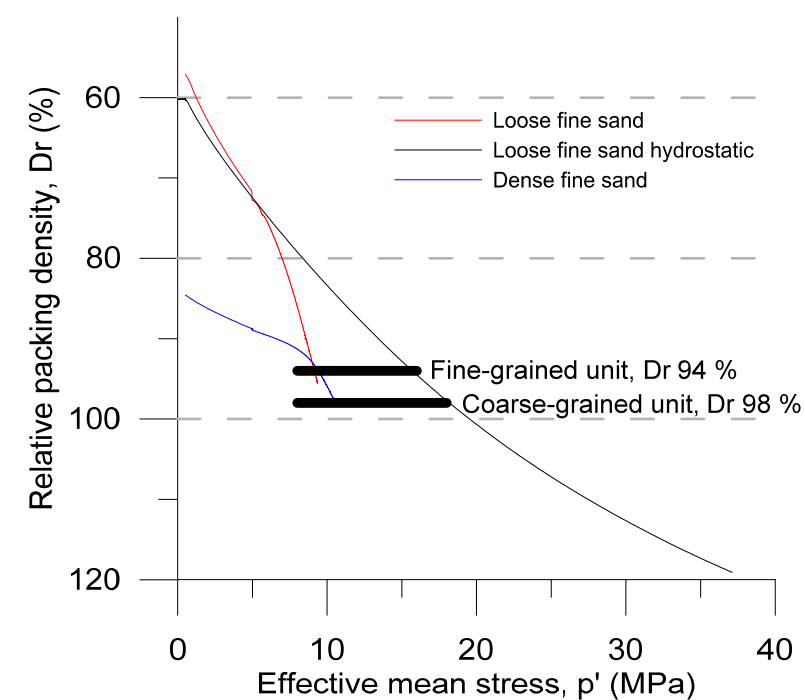

Fig. 7 Relative density as function of effective mean stress during different loading paths, hydrostatic and axial loading at 5 MPa confining stress. Estimated relative density for the two studied host rock units is added for the range of mean stress observed for the experimental data.

loading conditions, with shear loading as a more efficient packing than the hydrostatic loading. Relative packing density estimated for the host rock units is also shown in Fig. 7. Comparing the relative density evolution in the experimental curves with the relative density from the field, we observe that both the hydrostatic loading path and the axial loading at $5 \mathrm{MPa}$ confining pressure give a packing density similar to that estimated from field samples, but for very different mean stress levels.

\section{Discussion}

The inelastic deformation during formation of deformation bands can be described by a modified Cam-Clay cap model [52-53]. The theoretical framework for these modified Cam-Clay cap models is based on soil mechanical models describing the transition from elastic to plastic deformation [54], and further adopted to deformation bands observed in sandstone reservoirs [55-56]. The transition from brittle faulting to cataclastic flow in porous sandstone has been treated in numerous theoretical studies [53, 57-58] and explored through mechanical testing with a broad range of effective pressures [37, 59-61]. The experimental data are used to identify initiation of shear-enhanced dilation in the brittle regime and shear enhanced compaction resulting from cataclastic flow at high effective pressure. Experimental results are modelled utilizing the elliptical yield envelope comprising shear yield surface and cap, where the size of the cap is found to be controlled by the yield stress along a hydrostatic loading path. Wong et al. [39] found that the yield stress, $P^{*}$, is related to the onset of grain crushing and primarily controlled by the initial porosity and grain size of sandstone. Empirical prediction of onset of grain crushing and pore collapse is based on Hertzian fracturing in hydrostatic test conditions combined with the initial porosity and grain size [38]. In the following, we discuss the textural variations in porosity and grain size for the two sands studied and then compare our results using the end cap and yield stress model.

\subsection{Porosity and Packing Density}

Host rock porosity is considered as an important parameter for deformation band formation both in the field [6, 7, 36] and during laboratory testing [37], but the host rock porosity during deformation band formation is highly uncertain in Provence and for most studied field examples. In the present study we introduce packing density in order to compare the two units of significantly different porosity. The textural characterization in Table 1 shows that the average relative packing density, $D r$, estimated from present day porosity, shows a rather small difference $(D r=94 \%$ in fine-grained sand and $\mathrm{Dr}=98 \%$ in coarse-grained sand), and cannot explain the high porosity difference between the two units (porosity of $27.3 \%$ for the coarse-grained unit and $38.8 \%$ for the fine-grained unit). For the two units compared in this study, the grains are classified as similar in shape with only minor differences in angularity, whereas the main difference is grain size and sorting (Table 1). The lowest porosity is found for the sand with the wider grain size distribution (Table 1). This is in agreement with 
models describing porosity as being independent of grain size when all grains are of equal size, and decreases with an increasing range in grain size [62]. Well sorted materials are thus likely to have high porosities, whereas poor sorting makes for lower porosity. The porosity also increases when the particle shape differs from spherical; i.e., the lowest porosity is observed in grain aggregates showing high roundness and sphericity [63]. The slightly less rounded grains in the fine-grained sand (Fig. A1) might also contribute to the higher porosity of this unit. The similar packing density of the two units indicates that the final mechanical compaction related porosity is similar for the two units, whereas the difference in porosity between the two sand units is mainly related to textural characteristics (Fig. 8).

\subsection{Grain Size and Onset of Fracturing}

The theories developed for yield stress and localization of cataclastic deformation bands in sandstone are based on Hertzian fractures that localize on grain contacts $[38,64]$. One difference between the two Uchaux Sand units studied is the slightly more pronounced grain-crushing observed for the coarse-grained sand during mechanical testing (Fig. 6). The onset of grain fracturing can be related to the strength of single grains and the contact forces between them. Using a Hertzian model of normal compression of two identical spheres, it can be shown that for a hydrostatic confining pressure $P$ applied to a random, identical-sphere packing, the confining force $F$ acting between two particles is given by

$$
F=\frac{4 \pi R^{2} P}{C(1-n)}
$$

where, $R$ is the sphere radius, $C$ is the coordination number and $n$ is the porosity [49]. Applying Eq. (3) together with average values for porosity from the host rock, grain radius and coordination number for each material (Table 1) show that the coarse-grained material is subject to a higher force between the grains than the fine-grained sand (Table 2). This can be attributed to the fewer and larger grains resulting in fewer grain contacts within the same area [65]. The coarse-grained material is likely to have a large variation in the local, effective forces and shapes and sizes of contact-areas, based on the large spread in grain sizes.

The higher stress concentration on grain contacts for the coarse-grained material favors onset of grain fracturing and related yielding. This could be one important controlling parameter for the observed higher density of SECBs within the coarser-grained sand unit as compared to the finer-grained one. A more intense fracturing of coarse-grained sand as compared to fine-grained sand is also observed in experiments by Chuhan, et al. [51]. Based on the field observations, the few SECBs found in the fine-grained unit show grain fracturing and cataclasis, which is an indication

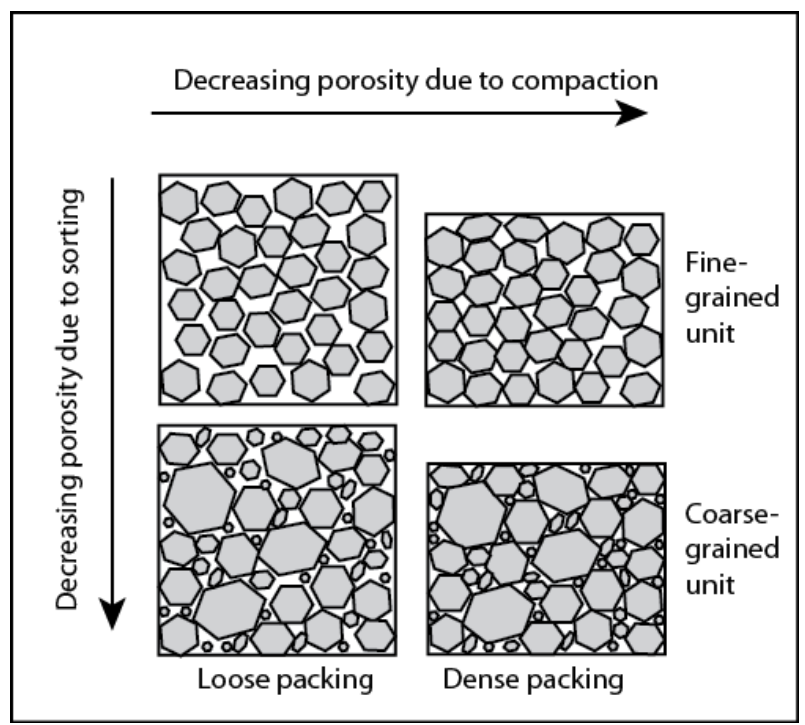

Fig. 8 Schematic illustration of the two factors (sedimentary (sorting) and compaction related) controlling the porosity of the two sand units.

Table 2 Characteristics of the two tested sands and the confining force calculated between two particles.

\begin{tabular}{llllll}
\hline \multirow{2}{*}{ Unit } & Confining pressure & Grain radius & Porosity & Coordination number & Confining force between two particles \\
& $P(\mathrm{MPa})$ & $R_{50}(\mathrm{~mm})$ & $\varphi$ & $C($ contacts/grain $)$ & $F(\mathrm{~N})$ \\
\hline Coarse-grained & 5 & 0.325 & 0.27 & 7.1 & $1.3 \times 10^{-3}$ \\
Fine-grained & 5 & 0.115 & 0.38 & 5.6 & $0.2 \times 10^{-3}$ \\
\hline
\end{tabular}


of forces on grain contacts being close to the grain fracturing pressure also for the fine-grained unit. Parts of the SECB observed in the fine-grained unit seem, however, to be propagating from the coarse-grained unit into the fine-grained unit, indicating that the bands could be generated by yield in the coarse-grained unit.

\subsection{End Cap Models and Yield Stress}

Cam-Clay yield envelopes are used to describe the elastic-plastic transition and shear-enhanced compaction bands formation in sandstone [53, 57-58]. The hydrostatic loading experiments (Fig. 7) show progressive change in packing density with increasing stress for the fine-grained sand units, allowing determination of unique end caps for this unit (Fig. 9). The end caps are presented using the $q-p^{\prime}$ diagram, where $q$ is the differential stress $(\sigma 1-\sigma 3)$ and $p^{\prime}$ is the effective mean stress $((\sigma 1+\sigma 2+\sigma 3) / 3-$ $p f$ ) in which $p f$ is the fluid pressure. Elliptical yield envelopes or end-caps can be calculated following Ref. [66] as used by Schultz and Siddharthan [52], where a symmetrical yield surface in $q-p^{\prime}$ space is defined as

$$
q^{2}=M^{2} p^{\prime}\left(p^{\prime}-P^{*}\right)
$$

Eq. (4) describes an ellipse representing the elastic-plastic boundary for the material controlled by a shape parameter $M$ and the size controlled by the yield stress $P^{*}$ along the hydrostatic loading path. The shape parameter $M$ defines a critical state line where the material deforms in a frictional manner, with no dilation or compaction, given by

$$
M=(6 \sin \varphi) /(3-\sin \varphi)
$$

where $\varphi$ is the Mohr-Coulomb friction angle for residual sliding. End caps are calculated using Eq. (4), and the critical state line $\mathrm{M}$ is defined using Eq. (5) and a friction angle of $28^{\circ}$ determined for the loosely packed fine-grained sand [45]. No distinct yield stress $P^{*}$ is observed for the hydrostatic test on loose sand (Table B1) and a pressure $P_{D r}$ representing various relative packing densities ( $D r$ 80\%, $D r$ 90\% and $\mathrm{Dr}$ $100 \%$ ) during the hydrostatic loading is used to calculate the end-caps. These end-caps represent stress conditions for which the material has equal packing density during different loading paths. The end-caps calculated for the fine-grained sand is found to fit well

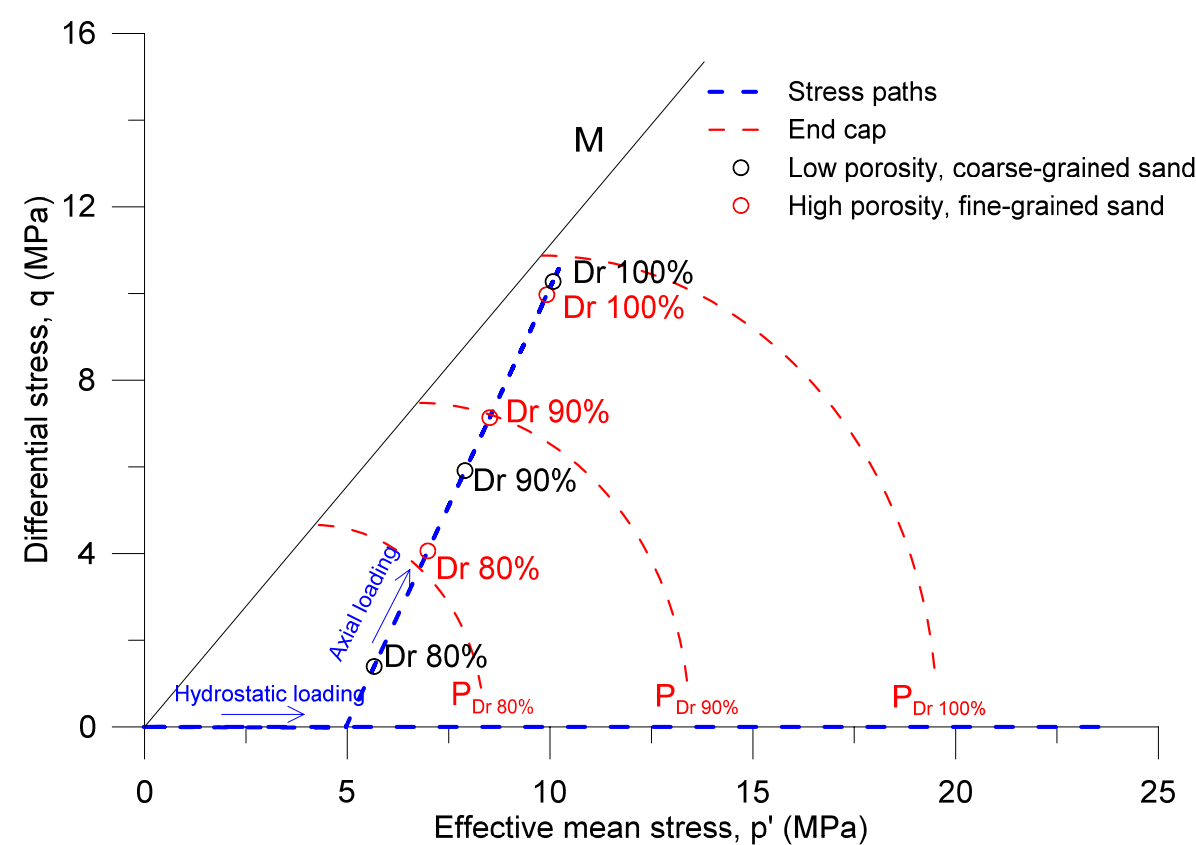

Fig. 9 Calculated end-caps for the loose fine-grained sand for pressure, $P_{D r}$, for selected relative densities during hydrostatic loading. The stress states during axial loading for selected relative densities are compared for the fine- and coarse-grained sand for tests with similar initial loose packing density. The loading stress needed for the low porosity, coarse-grained sand to reach the $\operatorname{Dr} \mathbf{8 0 \%}$ and $\mathrm{Dr} \mathbf{9 0 \%}$ state is lower than for the high porosity, fine-grained sand. 
with the measured relative density values of $\mathrm{Dr} 80 \%$, $\operatorname{Dr} 90 \%$ and $\operatorname{Dr} 100 \%$ along the axial loading path for the fine-grained sand. For comparison, measured relative density ( $\operatorname{~}$ 80\%, $\operatorname{Dr} 90 \%$ and $\operatorname{Dr} 100 \%$ ) is plotted for the coarse-grained sand along the same axial loading path as for the fine-grained sand (Fig. 9). End caps for the low porosity coarse-grained sand show lower stress conditions than the high porosity fine-grained sand when comparing the relative packing density (Fig. 9), although both sands approach the same relative packing density of $\mathrm{Dr} 100 \%$ when getting close to the critical state line. During initial compaction of the two sands, the coarse-grained material increases the packing density faster relative to the fine-grained material (Fig. 5 and Fig. 9), which suggests a potentially denser packing of the coarse-grained unit compared to the fine-grained unit at the time of SECBs formation. This difference in grain packing density may have been important for the deformation mechanism dominating in the unit, as porosity is important for the transition in deformation mechanism from grain rearrangement to grain fracturing [40, 45].

The yield stress, $P^{*}$ along the hydrostatic loading path described in Eq. (4), can be related to pore collapse and the grain crushing pressure [39]. Based on the finding from Ref. [38], the onset of grain crushing and pore collapse is related to the porosity and grain size. This relationship is used to calculate the yield stress, $P^{*}$ :

$$
P^{*}=(n R)^{-1.5}
$$

where, $n$ is the porosity and $R$ is the radius of the mean grain size. Yield stress calculated for the two sand units using Eq. (6) and the porosity and grain size from Table 1 show a higher calculated yield stress for the fine-grained material ( $100 \mathrm{MPa}$ ) than the coarse-grained material (20-40 MPa). The lower yield stress for the coarse-grained sand is consistent with the lower stress concentration on grain contacts in the fine-grained unit compared to the coarse-grained unit (Table 2), and also in agreement with the preferential formation of cataclastic SECBs observed for the coarse-grained unit. The large difference in calculated yield stress, $P^{*}$, and the stress conditions for the end caps presented in Fig. 9 is probably related to the difference in packing density and configuration between natural samples and the lab samples for the poorly lithified sands. Packing density is a parameter that correlates with the strength of sand [67], and is then also important for yield and strain localization in poorly lithified sandstone.

Comparable tests on similar type of poorly consolidated material, addressing shallow reservoirs conditions, is limited and with slightly different experimental setups $[34,68]$. Typical challenges for the approach in this work are the inability to identify a clear yield and localization of deformation bands during the mechanical testing. In addition, the gradual transition in deformation mechanism from grain rearrangement dominated to grain fracturing and crushing is difficult to identify [45] making the onset of grain fracturing is hard to identify. Future work is suggested to focus more on the visualization of cataclastic deformation. Mechanical testing of sand inside a x-ray computed tomography (CT) scanner has a good potential for identification of grain fracturing and porosity development inside deformation bands [69].

\section{Conclusion}

In this paper, we study and compare the preferential localization of shear-enhanced compaction bands in a coarse-grained and lower porosity sand unit versus a fine-grained high porosity unit. Based on field observations, detailed characterization of sand properties and mechanical testing, the following conclusions are made:

- Mineralogy and grain angularity of the two units is similar, whereas the better sorting of the fine-grained unit compared to the coarse-grained unit controls the porosity difference between the two units;

- The larger grain size of the coarse-grained material concentrate higher stresses on grain contacts and 
thereby controls the more intense grain fracturing and crushing observed for the coarse-grained material;

- Relative packing density is introduced as an important parameter in order to compare the compaction of sands with different textural characteristics. The two units show similar relative packing density with only a slightly higher density of the coarse-grained unit;

- Mechanical testing shows that the fine-grained and well sorted sand is stiffer during initial compaction than the coarse-grained sand. The coarse-grained and less well sorted sand shows faster relative compaction than the fine-grained sand in the initial compaction phase;

- The preferential localization of SECB in the coarse-grained unit is thought to be controlled by two factors: (1) higher stress concentration on grain contacts, mainly controlled by the grain size, initiating grain fracturing and (2) faster compaction and increase in relative density reducing the potential for distributed deformation;

- The presented approach compares deformation during experimental compaction with observations of localization deformation from field outcrop of two textually different sandstones. The work benefits from the possibility to do the experimental work on the same material as studied in outcrop, whereas the main drawback of the study is the inability to identified localized deformation bands within the experimentally deformed samples.

\section{Acknowledgments}

This study is part of a consortium research and development project 207806 (Impact of fault rock properties on $\mathrm{CO}_{2}$ storage in sandstone reservoirs Project) at Uni Research, Centre for Integrated Petroleum Research, funded by the CLIMIT Program at the Research Council of Norway and Statoil. Support from AREVA NC is also acknowledged. Thanks to R. H. Gabrielsen, P. Eichhubl and S. Cashman for comments on an early version of the manuscript.

\section{References}

[1] Aydin, A., and Johnson, A. M. 1978. "Development of Faults as Zones of Deformation Bands and as Slip Surfaces in Sandstone.” Pure and Applied Geophysics 116 (4-5): 931-42.

[2] Tondi, E., Antonellini, M., Aydin, A., Marchegiani, L., and Cello, G. 2006. "The Role of Deformation Bands, Stylolites and Sheared Stylolites in Fault Development in Carbonate Grainstones of Majella Mountain, Italy." Journal of Structural Geology 28 (3): 376-91.

[3] Wennberg, O. P., Casini, G., Jahanpanah, A., Lapponi, F., Ineson, J., Wall, B. G., and Gillespie, P. 2013. "Deformation Bands in Chalk, Examples from the Shetland Group of the Oseberg Field, North Sea, Norway." Journal of Structural Geology 56 (November): 103-17.

[4] Wilson, J. E., Goodwin, L. B., and Lewis, C. J. 2003. "Deformation Bands in Nonwelded Ignimbrites: Petrophysical Controls on Fault-Zone Deformation and Evidence of Preferential Fluid Flow.” Geology 31 (10): 837-40.

[5] Fossen, H., Schultz, R. A., Shipton, Z. K., and Mair, K. 2007. "Deformation Bands in Sandstone: A Review." Journal of the Geological Society 164 (4): 755-69.

[6] Antonellini, M. A., Aydin, A., and Pollard, D. D. 1994. "Microstructure of Deformation Bands in Porous Sandstones at Arches National-Park, Utah.” Journal of Structural Geology 16 (7): 941-59.

[7] Fisher, Q. J., and Knipe, R. 2001. "The Permeability of Faults within Siliciclastic Petroleum Reservoirs of the North Sea and Norwegian Continental Shelf.” Marine and Petroleum Geology 18 (10): 1063-81.

[8] Tueckmantel, C., Fisher, Q. J., Grattoni, C. A., and Aplin, A. C. 2012. "Single- and Two-Phase Fluid Flow Properties of Cataclastic Fault Rocks in Porous Sandstone.” Marine and Petroleum Geology 29 (1): 129-42.

[9] Fossen, H., and Bale, A. 2007. "Deformation Bands and Their Influence on Fluid Flow.” Aapg Bulletin 91 (12): 1685-700.

[10] Torabi, A., and Fossen, H. 2009. "Spatial Variation of Microstructure and Petrophysical Properties along Deformation Bands in Reservoir Sandstones.” Aapg Bulletin 93 (7): 919-38.

[11] Torabi, A., Fossen, H., and Braathen, A. 2013. "Insight into Petrophysical Properties of Deformed Sandstone Reservoirs.” Aapg Bulletin 97 (4): 619-37.

[12] Eichhubl, P., Hooker, J. N., and Laubach, S. E. 2010. "Pure and Shear-Enhanced Compaction Bands in Aztec Sandstone.” Journal of Structural Geology 32 (12): 1873-86. 
[13] Ballas, G., Soliva, R., Sizun, J. P., Fossen, H., Benedicto, A., and Skurtveit, E. 2013. "Shear-Enhanced Compaction Bands Formed at Shallow Burial Conditions; Implications for Fluid Flow (Provence, France).” Journal of Structural Geology 47 (February): 3-15.

[14] Braathen, A., Tveranger, J., Fossen, H., Skar, T., Cardozo, N., Semshaug, S. E., Bastesen, E., and Sverdrup, E. 2009. "Fault Facies and Its Application to Sandstone Reservoirs." Aapg Bulletin 93 (7): 891-917.

[15] Fredman, N., Tveranger, J., Semshaug, S., Braathen, A., and Sverdrup, E. 2007. "Sensitivity of Fluid Flow to Fault Core Architecture and Petrophysical Properties of Fault Rocks in Siliciclastic Reservoirs: A Synthetic Fault Model Study.” Petroleum Geoscience 13 (4): 305-20.

[16] Manzocchi, T., Heath, A. E., Palananthakumar, B., Childs, C., and Walsh, J. J. 2008. "Faults in Conventional Flow Simulation Models: A Consideration of Representational Assumptions and Geological Uncertainties.” Petroleum Geoscience 14 (1): 91-110.

[17] Bachu, S., Bonijoly, D., Bradshaw, J., Burruss, R., Holloway, S., Christensenf, N. P., and Mathiasseng, O. M. 2007. " $\mathrm{CO}_{2}$ Storage Capacity Estimation: Methodology and Gaps.” International Journal of Greenhouse Gas Control 1 (4): 430-43.

[18] Cappa, F., and Rutqvist, J. 2011. "Modeling of Coupled Deformation and Permeability Evolution during Fault Reactivation Induced by Deep Underground Injection of $\mathrm{CO}_{2}$." International Journal of Greenhouse Gas Control 5 (2): 336-46.

[19] Rutqvist, J., Birkholzer, J., and Tsang, C. F. 2008. "Coupled Reservoir-Geomechanical Analysis of the Potential for Tensile and Shear Failure Associated with $\mathrm{CO}_{2}$ Injection in Multilayered Reservoir-Caprock Systems.” International Journal of Rock Mechanics and Mining Sciences 45 (2): 132-43.

[20] Soliva, R., Schultz, R. A., Ballas, G., Taboada, A., Wibberley, C., Sailletd, E., and Benedictoe, A. 2013. “A Model of Strain Localization in Porous Sandstone as a Function of Tectonic Setting, Burial and Material Properties; New Insight from Provence (Southern France).” Journal of Structural Geology 49 (April): 50-63.

[21] Aydin, A., Borja, R. I., and Eichhubl, P. 2006. "Geological and Mathematical Framework for Failure Modes in Granular Rock.” Journal of Structural Geology 28 (1): 83-98.

[22] Bernard, X. D., Eichhubl, P., and Aydin, A. 2002. "Dilation Bands: A New Form of Localized Failure in Granular Media.” Geophysical Research Letters 29 (24): 2176.

[23] Solum, J. G., Brandenburg, J. P., Naruk, S. J., Kostenko, O. V., Wilkins, S. J., and Schultz, R. A. 2010. "Characterization of Deformation Bands Associated with Normal and Reverse Stress States in the Navajo Sandstone,
Utah.” Aapg Bulletin 94 (9): 1453-75.

[24] Saillet, E., and Wibberley, C. A. J. 2010. "Evolution of Cataclastic Faulting in High-Porosity Sandstone, Bassin du Sud-Est, Provence, France.” Journal of Structural Geology 32 (11): 1590-608.

[25] Ballas, G., Soliva, R., Benedicto, A., and Sizun, J. P. 2014. "Control of Tectonic Setting and Large-Scale Faults on the Basin-Scale Distribution of Deformation Bands in Porous Sandstone (Provence, France)." Marine and Petroleum Geology 55 (August): 142-59.

[26] Fisher, Q. J., Casey, M., Harris, S. D., and Knipe, R. J. 2003. "Fluid-Flow Properties of Faults in Sandstone: The Importance of Temperature History." Geology 31 (11): 965-8.

[27] Johansen, T. E. S., Fossen, H., and Kluge, R. 2005. “The Impact of Syn-Faulting Porosity Reduction on Damage Zone Architecture in Porous Sandstone: An Outcrop Example from the Moab Fault, Utah.” Journal of Structural Geology 27 (8): 1469-85.

[28] Fossen, H. 2010. "Deformation Bands Formed during Soft-Sediment Deformation: Observations from SE Utah.” Marine and Petroleum Geology 27 (1): 215-22.

[29] Sternlof, K. R., Rudnicki, J. W., and Pollard, D. D. 2005. "Anticrack Inclusion Model for Compaction Bands in Sandstone.” Journal of Geophysical Research-Solid Earth 110 (B11): 1-16.

[30] Kristensen, M. B., Childs, C., Olesen, N. Ø., and Korstgård, J. A. 2013. "The Microstructure and Internal Architecture of Shear Bands in Sand-Clay Sequences.” Journal of Structural Geology 46 (January): 129-41.

[31] Hesthammer, J., and Fossen, H. 2001. "Structural Core Analysis from the Gullfaks Area, Northern North Sea.” Marine and Petroleum Geology 18 (3): 411-39.

[32] Ballas, G., Soliva, R., Sizun, J. P., Benedict, A., Cavailhes, T., and Raynaud, S. 2012. "The Importance of the Degree of Cataclasis in Shear Bands for Fluid Flow in Porous Sandstone, Provence, France.” Aapg Bulletin 96 (11): 2167-86.

[33] Cashman, S., and Cashman, K. 2000. "Cataclasis and Deformation-Band Formation in Unconsolidated Marine Terrace Sand, Humboldt County, California.” Geology 28 (2): 111-4.

[34] Kaproth, B. M., Cashman, S. M., and Marone, C. 2010. "Deformation Band Formation and Strength Evolution in Unlithified Sand: The Role of Grain Breakage.” Journal of Geophysical Research: Solid Earth 115 (B12): 1-11.

[35] Mollema, P. N., and Antonellini, M. A. 1996. "Compaction Bands: A Structural Analog for Anti-Mode I Cracks in Aeolian Sandstone.” Tectonophysics 267 (1-4): 209-28.

[36] Fossen, H., Schultz, R. A., and Torabi, A. 2011. "Conditions and Implications for Compaction Band Formation in the Navajo Sandstone, Utah.” Journal of 
Structural Geology 33 (10): 1477-90.

[37] Wong, T. F., and Baud, P. 2012. "The Brittle-Ductile Transition in Porous Rock: A Review." Journal of Structural Geology 44 (November): 25-53.

[38] Zhang, J. X., Wong, T. F., and Davis, D. M. 1990. "Micromechanics of Pressure-Induced Grain Crushing in Porous Rocks.” Journal of Geophysical Research-Solid Earth and Planets 95 (B1): 341-52.

[39] Wong, T. F., David, C., and Zhu, W. L. 1997. "The Transition from Brittle Faulting to Cataclastic Flow in Porous Sandstones: Mechanical Deformation.” Journal of Geophysical Research-Solid Earth 102 (B 2): 3009-25.

[40] Karner, S. L., Chester, J. S., Chester, F. M., Kronenberg, A. K., and Jr, A. H. 2005. "Laboratory Deformation of Granular Quartz Sand: Implications for the Burial of Clastic Rocks.” Aapg Bulletin 89 (5): 603-25.

[41] Estrada, N., Azéma, E., Radjai, F., and Taboada, A. 2011. "Identification of Rolling Resistance as a Shape Parameter in Sheared Granular Media.” Physical Review E 84 (1): 1-5.

[42] Wang, B., Chen, Y., and Wong, T. F. 2008. “A Discrete Element Model for the Development of Compaction Localization in Granular Rock.” Journal of Geophysical Research: Solid Earth 113 (B 3): 1-17.

[43] Cheung, C. S., Baud, P., and Wong, T. F. 2012. "Effect of Grain Size Distribution on the Development of Compaction Localization in Porous Sandstone.” Geophysical Research Letters 39 (21): 1-5.

[44] Mair, K., Frye, K. M., and Marone, C. 2002. "Influence of Grain Characteristics on the Friction of Granular Shear Zones.” Journal of Geophysical Research: Solid Earth 107 (B 10): ECV 4-1-ECV 4-9.

[45] Skurtveit, E., Torabi, A., Gabrielsen, R. H., and Zoback, M. D. 2013. "Experimental Investigation of Deformation Mechanisms during Shear-Enhanced Compaction in Poorly Lithified Sandstone and Sand.” Journal of Geophysical Research: Solid Earth 118 (8): 4083-100.

[46] Sibson, R. 1977. "Fault Rocks and Fault Mechanisms." Journal of the Geological Society 133 (3): 191-213.

[47] Cox, M. R., and Budhu, M. 2008. "A Practical Approach to Grain Shape Quantification.” Engineering Geology 96 (1): 1-16.

[48] Oda, M., and Iwashita, K. 1999. Mechanics of Granular Materials: An Introduction. UK, USA, Singapore and Australia: Taylor \& Francis.

[49] Mavko, G., Mukerji, T., and Dvorkin, J. 2009. The Rock Physics Handbook. New York: Cambridge University Press.

[50] Cornforth, D. 1973. "Prediction of Drained Strength of Sands from Relative Density Measurements.” ASTM STP 523 (July): 281-303.

[51] Chuhan, F. A., Kjeldstad, A., Bjørlykke, K., and Høeg, K. 2002. "Porosity Loss in Sand by Grain Crushing - Experimental
Evidence and Relevance to Reservoir Quality.” Marine and Petroleum Geology 19 (1): 39-53.

[52] Schultz, R. A., and Siddharthan, R. 2005. “A General Framework for the Occurrence and Faulting of Deformation Bands in Porous Granular Rocks.” Tectonophysics 411 (1-4): 1-18.

[53] Rudnicki, J. W. 2004. "Shear and Compaction Band Formation on an Elliptic Yield Cap." Journal of Geophysical Research: Solid Earth 109 (B3): 1-10.

[54] Bésuelle, P., and Rudnicki, J. W. 2003. "Chapter 5 Localization: Shear Bands and Compaction Bands.” In International Geophysics, edited by Yves, G., and Maurice, B. Burlington: Academic Press.

[55] Rudnicki, J. W., and Rice, J. R. 1975. "Conditions for Localization of Deformation in Pressure-Sensitive Dilatant Materials.” Journal of the Mechanics and Physics of Solids 23 (6): 371-94.

[56] Aydin, A., and Johnson, A. M. 1983. "Analysis of Faulting in Porous Sandstones.” Journal of Structural Geology 5 (1): 19-31.

[57] Bésuelle, P. 2001. "Compacting and Dilating Shear Bands in Porous Rock: Theoretical and Experimental Conditions." Journal of Geophysical Research: Solid Earth 106 (B 7): 13435-42.

[58] Issen, K., and Rudnicki, J. 2000. "Conditions for Compaction Bands in Porous Rock." Journal of Geophysical Research 105 (B 9): 21,529-36.

[59] Fortin, J., Schubnel, A., and Gueguen, Y. 2005. "Elastic Wave Velocities and Permeability Evolution during Compaction of Bleurswiller Sandstone.” International Journal of Rock Mechanics and Mining Sciences 42 (7-8): 873-89.

[60] Baud, P., Klein, E., and Wong, T. F. 2004. "Compaction Localization in Porous Sandstones: Spatial Evolution of Damage and Acoustic Emission Activity." Journal of Structural Geology 26 (4): 603-24.

[61] Tembe, S., Baud, P., and Wong, T. F. 2008. "Stress Conditions for the Propagation of Discrete Compaction Bands in Porous Sandstone.” Journal of Geophysical Research: Solid Earth (1978-2012) 113 (B 9): 1-16.

[62] Beard, D., and Weyl, P. 1973. "Influence of Texture on Porosity and Permeability of Unconsolidated Sand.” Aapg Bulletin 57 (2): 349-69.

[63] Cho, G. C., Dodds, J., and Santamarina, J. C. 2006. "Particle Shape Effects on Packing Density, Stiffness, and Strength: Natural and Crushed Sands.” Journal of Geotechnical and Geoenvironmental Engineering 132 (5): 591-602.

[64] Sammis, C., King, G., and Biegel, R. 1987. "The Kinematics of Gouge Deformation.” Pure and Applied Geophysics 125 (5): 777-812.

[65] Balsamo, F., and Storti, F. 2011. "Size-Dependent Comminution, Tectonic Mixing, and Sealing Behavior of 
a "Structurally Oversimplified" Fault Zone in Poorly Lithified Sands: Evidence for a Coseismic Rupture?” Geological Society of America Bulletin 123 (3-4): 601-19.

[66] Davis, R. O., and Selvadurai, A. P. 2002. Plasticity and Geomechanics. Cambridge: Cambridge University Press.

[67] Bolton, M. 1986. "The Strength and Dilatancy of Sands." Geotechnique 36 (1): 65-78.

[68] Crawford, B., Gooch, M., and Webb, D. 2004. "Textural Controls on Constitutive Behavior on Unconsolidated Sands: Micromechanics and Cap Plasticity.” Presented at the 6th NARMS (North America Rock Mechanics
Symposium), Houston, Texas.

[69] Alikarami, R. 2014. "Strain Localisation in Sand and Porous Sandstone.” in Centre for Integrated petroleum Research (Uni CIPR) and Department of Earth Science. University of Bergen: AIT OSLO AS.

[70] Mora, C., and Kwan, A. 2000. "Sphericity, Shape Factor, and Convexity Measurement of Coarse Aggregate for Concrete Using Digital Image Processing." Cement and Concrete Research 30 (3): 351-8.

[71] Berre, T. 2011. "Triaxial Testing of Soft Rocks." Geotechnical Testing Journal 34 (1): 61-75.

\section{Appendix A: Grain Angularity Quantification.}

Grain angularity quantification is performed by using an automatic image processing on optical photomicrographs with a representative number of grains: 27 for the coarse-grained sandstone and 40 for the fine-grained sandstone. The grain selection is performed manually. Several morphologic descriptors have been proposed for quantifying grain shapes, and degree of roundness [47, 70]. All these morphologic parameters are defined as ratios of various geometric dimensions, and equal 1 for a perfect spherical grain. In this study, we use the morphologic parameters listed in Table A1. For each parameter, we estimate the mean value and the standard deviation for each material (Table A1).

The tested parameters for grain angularity show similar values for both units, although the coarse-grained material shows slightly higher compactness, roundness, modification ratio and sphericity, whereas the fine-grained material shows slightly higher aspect ratio and circularity (Fig. A1). Nevertheless, a simple statistical Student's test (or equivalently a $z$-test) clearly states no statistical significant difference in shape parameter for the two different materials tested (Table A1). It is thus concluded that the two sands have similar shape properties. Comparing our results with sands described in Ref. [47] shows that both sands have shape parameters similar to rounded sand, and can be classified as sub-rounded to rounded grains (Fig. A1).

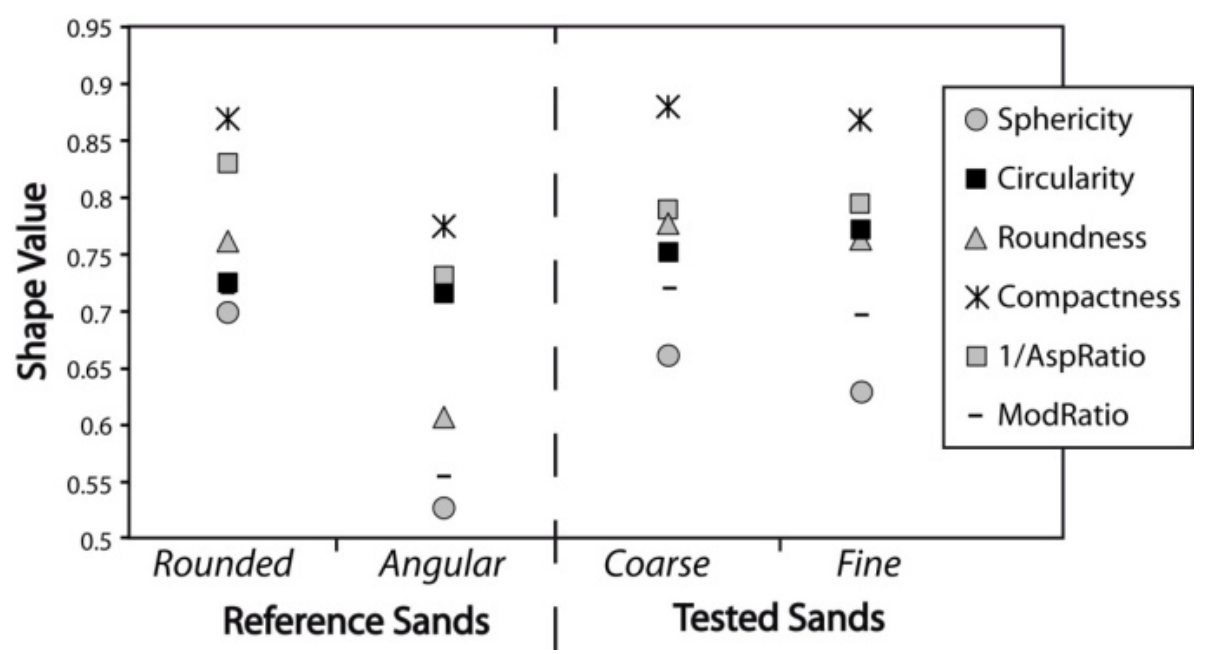

Fig. A1 Graph showing the different shape parameters measured on grains from each sand unit. Shape parameters of standard rounded and angular sand from Ref. [47] are also plotted to compare with the coarse- and fine-grained sand tested. 
Table A1 Shape parameters and mathematical expressions used for the grain angularity analysis together with the mean value and standard deviation measured for the coarse-grained and fine-grained sand. The $p$-values of the two-sample Student's test are also given. Mathematical factors used are: area $A$, and the perimeter of one grain $P$, the area of its convex hull, Convex Area, the length $L_{\min }$ and width $L_{\max }$ of the smallest rectangle enclosing the grain, the minor and major axes of the best fitting ellipse, Minor Axis and Major Axis, respectively, and the radius of the maximum inscribed and minimum circumscribed circles, $R_{I}$ and $R_{C}$, respectively.

\begin{tabular}{|c|c|c|c|c|c|c|}
\hline \multirow{2}{*}{$\begin{array}{l}\text { Shape parameter } \\
\text { Sphericity }\end{array}$} & Math. expression & \multicolumn{2}{|c|}{$\begin{array}{l}\text { Coarse-grained sand } \\
\text { Mean and standard deviation }\end{array}$} & \multicolumn{2}{|c|}{$\begin{array}{l}\text { Fine-grained sand } \\
\text { Mean and standard deviation }\end{array}$} & \multirow{2}{*}{$\begin{array}{l}p \text {-value } \\
\text { Student's test } \\
0.33\end{array}$} \\
\hline & $\frac{R_{I}}{R_{C}}$ & 0.65 & 0.06 & 0.63 & 0.09 & \\
\hline Circularity & $\frac{4 \pi A}{P^{2}}$ & 0.75 & 0.04 & 0.77 & 0.05 & 0.11 \\
\hline Modification ratio & $\frac{2 R_{I}}{\text { MajorAxis }}$ & 0.70 & 0.07 & 0.69 & 0.10 & 0.42 \\
\hline Feret compactness & $\begin{array}{c}\frac{\sqrt{4 \cdot A}}{\pi \cdot L_{\max }} \\
4 \cdot A\end{array}$ & 0.88 & 0.06 & 0.87 & 0.08 & 0.63 \\
\hline Feret roundness & $\frac{4 \cdot A}{\left(\pi \cdot L_{\max }\right)^{2}}$ & 0.78 & 0.11 & 0.76 & 0.13 & 0.67 \\
\hline (Feret aspect ratio) $^{-1}$ & $\frac{L_{\min }}{L_{\max }}$ & 0.77 & 0.03 & 0.75 & 0.03 & 0.15 \\
\hline Solidity & 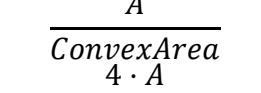 & 0.97 & 0.02 & 0.96 & 0.02 & 0.41 \\
\hline Ellipse roundness & $\overline{(\pi \cdot \text { MajorAxis })^{2}}$ & 0.74 & 0.08 & 0.72 & 0.11 & 0.49 \\
\hline Ellipse compactness & $\frac{\sqrt{4 \cdot A}}{\pi \cdot \text { MajorAxis }}$ & 0.86 & 0.05 & 0.85 & 0.07 & 0.45 \\
\hline (Ellipse aspect ratio) $^{-1}$ & $\frac{\text { MinorAxis }}{\text { MajorAxis }}$ & 0.76 & 0.09 & 0.74 & 0.12 & 0.47 \\
\hline
\end{tabular}

Appendix B: Experimental Details.

Tests were performed in the laboratory at the NGI (Norwegian Geotechnical Institute) using a triaxial setup measuring axial and radial deformation [71]. The tests were performed using drained conditions and a backpressure of $1 \mathrm{MPa}$. Axial and radial strain were measured using LVDT (linear variable differential transformer) sensors. The hydrostatic test samples were loaded isotropically up to 40 MPa, whereas for the axial compression tests, a differential stress was imposed after hydrostatic loading to the confining pressure. Details about the test set-up and methodology are given in Ref. [45], together with interpretation of yield stress and discussion of deformation mechanism. An overview of the test presented and discussed in this paper is given in Table B1.

Table B1 Initial packing density, relative density, porosity together with loading path, confining stress and interpreted yield stress for the tests presented in this work. Test methodology, results and interpretation are presented in Ref. [45].

\begin{tabular}{lllllll}
\hline \multirow{2}{*}{ Sample } & Packing density $\begin{array}{l}\text { Dr } \\
(\%)\end{array}$ & $\begin{array}{l}\text { Initial porosity } \\
(\%)\end{array}$ & Loading conditions & $\begin{array}{l}\text { Confining stress } \\
(\mathrm{MPa})\end{array}$ & $\begin{array}{l}\text { Yield stress, } P \\
(\mathrm{MPa})\end{array}$ \\
\cline { 2 - 7 } & & & & & & - \\
\hline Coarse-grained sand* & Loose & 55 & 36 & Axial compression & 5 & - \\
Fine-grained sand & Loose & 54 & 46 & Axial compression & 5 & 8.8 \\
Fine-grained sand & Dense & 84 & 41 & Axial compression & 5 & - \\
Fine-grained sand & Loose & 58 & 46 & Hydrostatic & 40 & \\
\hline
\end{tabular}

* This test is not included in Ref. [45]. Test procedures are similar as for the loose fine-grained sample. 